\title{
The combination of the prodrugs perforin-CEBPD and perforin-granzyme $B$ efficiently enhances the activation of caspase signaling and kills prostate cancer
}

\author{
C-H Chuang ${ }^{1,14}$, W-J Wang ${ }^{2,14}$, C-F Li ${ }^{3,4,5,14}$, C-Y Ko ${ }^{6,7}$, Y-H Chou ${ }^{8}$, C-P Chuu ${ }^{9}$, T-L Cheng, and J-M Wang ${ }^{\star, 10,11,12,13}$
}

The survival of prostate cancer ( $\mathrm{PrCa}$ ) patients is associated with the transition to hormone-independent tumor growth and metastasis. Clinically, the dysregulation of androgen action has been associated with the formation of $\mathrm{PrCa}$ and the outcome of androgen deprivation therapy in PrCa. CCAAT/enhancer binding protein delta (CEBPD) is a transcription factor that has been reported to act as an oncogene or tumor suppressor, depending on the extra- and intracellular environments following tumorigenesis. We found that androgen can activate CEBPD transcription by direct binding of the androgen receptor (AR) to the CEBPD promoter region. Increases of suppressor of zeste 12 (SUZ12) and enhancer of zeste homolog 2 (EZH2) attenuated the androgen-induced transcription of CEBPD. Importantly, the increases in E2F1, SUZ12 and EZH2 as well as the inactivation of CEBPD were associated with the clinicopathological variables and survival of PrCa patients. We revealed that caspase 8 (CASP8), an apoptotic initiator, is responsive to CEBPD induction. Reporter and in vivo DNA-binding assays revealed that CEBPD directly binds to and activates CASP8 reporter activity. A prodrug system was developed for therapeutic application in AR-independent or androgen-insensitive PrCa to avoid the epigenetic effects on the suppression of CEBPD expression. Our results showed that the combination of a perforin (PF)-CEBPD prodrug (which increases the level of procaspase-8) and a PF-granzyme B prodrug (which activates CASP8 and caspase 3 (CASP3)) showed an additive effect in triggering the apoptotic pathway and enhancing apoptosis in PrCa cells.

Cell Death and Disease (2014) 5, e1220; doi:10.1038/cddis.2014.106; published online 8 May 2014

Subject Category: Cancer

Androgen is important for the development and maintenance of the prostate and has an important role in the progression of prostate cancer (PrCa). Androgen receptor (AR) is an androgen-activated transcription factor belonging to the nuclear receptor superfamily. Dihydrotestosterone (DHT), a hormone with powerful androgenic actions, binds to the AR, induces the dissociation of AR from heat-shock proteins and activates AR contribution in transcriptional regulation. ${ }^{1}$ The standard therapies for PrCa include androgen ablation, which initially causes tumor regression. However, $80-90 \%$ of the patients who receive androgen ablation therapy will eventually relapse and develop castration-resistant PrCa (CRPC). Recently, it has been proposed that ongoing steroidogenesis within prostate tumors and the maintenance of intratumoral androgens may contribute to castration-resistant growth. ${ }^{2}$ However, the details of this mechanism remain largely unknown.

Depending on the mechanisms of the response to androgen and the absence or presence of the AR, the types of PrCa can be classified as follows: androgen dependent/AR dependent

\footnotetext{
${ }^{1}$ Department of Biomedical Science and Environmental Biology, Kaohsiung Medical University, Kaohsiung, Taiwan; ${ }^{2}$ Institute of Basic Medical Science, National Cheng Kung University, Tainan, Taiwan; ${ }^{3}$ Department of Pathology, Chi-Mei Medical Center, Tainan, Taiwan; ${ }^{4}$ National Institute of Cancer Research, National Health Research Institutes, Tainan, Taiwan; ${ }^{5}$ Institute of Clinical Medicine, Kaohsiung Medical University, Kaohsiung, Taiwan; ${ }^{6}$ PhD Program for Neural Regenerative Medicine, College of Medical Science and Technology, Taipei Medical University, Taipei, Taiwan; ${ }^{7}$ Center for Neurotrauma and Neuroregeneration, Taipei Medical University, Taipei, Taiwan; ${ }^{8}$ Department of Pharmacology, National Cheng Kung University, Tainan, Taiwan; ${ }^{9}$ Institute of Cellular and System Medicine, National Health Research Institutes, Miaoli, Taiwan; ${ }^{10}$ Institute of Bioinformatics and Biosignal Transduction, College of Bioscience and Biotechnology, National Cheng Kung University, Tainan, Taiwan; ${ }^{11}$ Infectious Disease and Signaling Research Center, National Cheng Kung University, Tainan, Taiwan; ${ }^{12}$ Center of Molecular Inflammation, National Cheng Kung University, Tainan, Taiwan and ${ }^{13}$ Graduate Institute of Medical Sciences, College of Medicine, Taipei Medical University, Taipei, Taiwan

${ }^{*}$ Corresponding author: T-L Cheng, Departments of Biomedical Science and Environmental Biology, Kaohsiung Medical University, Kaohsiung 807, Taiwan. Tel: +886 73121101 2697; Fax: +886 7 3227508; E-mail: tlcheng@ kmu.edu.tw

or J-M Wang, Institute of Bioinformatics and Biosignal Transduction, College of Bioscience and Biotechnology, National Cheng Kung University, Tainan 701, Taiwan. Tel: +886 62757575 31067; Fax: +886 6 2083663; E-mail: yumingw@ mail.ncku.edu.tw

${ }^{14}$ These authors contributed equally to this study.

Keywords: prostate cancer; androgen; CEBPD; epigenetic regulation; prodrug

Abbreviations: PrCa, prostate cancer; CEBPD, CCAAT/enhancer binding protein delta; AR, androgen receptor; SUZ12, suppressor of Zeste 12; EZH2, enhancer of zeste homolog 2; CASP8, caspase 8; CASP3, caspase 3; tBID, truncated BH3 interacting domain death agonist; DHT, dihydrotestosterone; CRPC, castration-resistant PrCa; PSA, prostate-specific antigen; MMPs, matrix metalloproteinases; Caspases, cysteine-dependent aspartate-directed proteases; FasL, fas ligand; PI, propidium iodide; PF, perforin; CREB, CAMP response element binding protein; Fbxw7, F-box/WD repeat-containing protein 7; SCF, Skp1/Cullin/F-box protein

Received 19.11.13; revised 11.2.14; accepted 11.2.14; Edited by A Stephanou
} 
(androgen sensitive/AR positive), androgen dependent/AR independent (androgen sensitive/AR negative), androgen independent/AR dependent (androgen insensitive/AR positive) and androgen independent/AR independent (androgen insensitive/AR negative). ${ }^{1}$ LNCaP, an AR-positive/sensitive PrCa cell line, and PC3, an AR-negative/insensitive PrCa cell line, express prostate-specific antigen (PSA) and serve as a model cell lines for the study of androgen-related $\mathrm{PrCa}$. In addition, androgen-insensitive metastatic prostate tumors showed a sustained AR expression and the amplification of the AR gene was observed in $30 \%$ of metastatic prostate

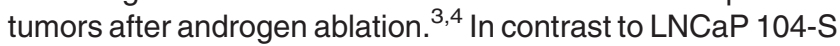
cells (an androgen-dependent clonal isolation of the LNCaP cell line), 104-R1 cells can proliferate in the absence of androgen and continue to express high levels of functional $\mathrm{AR}^{5}$

CCAAT/enhancer binding protein delta (CEBPD) is a member of the C/EBP family that acts as a transcription factor in tissue differentiation, metabolism and immune responses. CEBPD is expressed at a relatively low level under normal physiological conditions and is upregulated by a variety of extracellular stimuli, such as interleukin-6, lipopolysaccharide, interleukin-1 beta, tumor necrosis factor alpha, interferon-alpha and interferon-gamma. The overexpression of CEBPD can induce growth arrest and apoptosis in cancer cells. ${ }^{6}$ Moreover, an increase in mammary tumor multiplicity was observed in $\mathrm{Cebpd}^{-1-} / \mathrm{HER} 2 /$ neu mice. ${ }^{7}$ These results indicated that CEBPD may be a tumor suppressor. CEBPD has been reported to be activated in response to chemotherapeutic anticancer drugs. ${ }^{8-10}$ Interestingly, it was recently suggested that CEBPD also acts as an oncogene under certain conditions such as hypoxia and inflammation. ${ }^{7,11}$

Unlike the inflammatory-responsive transcription factors NF- $\kappa B$ and STAT3, which are consistently activated after tumorigenesis, the inactivation of CEBPD has been observed in many cancers, including breast cancer, liver cancer, cervical cancer and leukemia. ${ }^{6,12-14}$ The inactivation of CEBPD also has been observed in PrCa. ${ }^{10}$ E2F1 is significantly elevated in metastatic tissues from hormoneresistant $\mathrm{PrCa} .{ }^{15}$ The epigenetic regulators enhancer of zeste homolog 2 (EZH2) and suppressor of zeste 12 (SUZ12) are responsive to an increase in E2F1 levels. ${ }^{16} \mathrm{EZH} 2$ has been reported to be a H3K27 methyltransferase, and SUZ12 is essential for EZH2 histone methyltransferase activity. ${ }^{17}$ A recent study suggested that SUZ12 and EZH2 can recruit DNA methyltransferases and attenuate CEBPD transcription via DNA and histone methylation. ${ }^{6}$ However, the E2F1mediated increases in SUZ12 and EZH2 regulate CEBPD silencing in PrCa and the potential for therapeutic applications of CEBPD activation in PrCa remains unknown.

Proteases contribute to cancer promotion and development by remodeling the extracellular matrix. PSA is a substance that is produced by the prostate gland. Elevated PSA levels may indicate either PrCa or a noncancerous condition such as prostatitis or an enlarged prostate. MMP-2 belongs to the gelatinase subfamily of the matrix metalloproteinases (MMPs) and, of note, has been identified as one of the key MMPs that are capable of degrading type-IV collagen, the major component of basement membranes. A significant activation of MMP2 has been observed in PrCa. ${ }^{18,19}$
Cysteine-dependent aspartate-directed proteases (caspases) are a family of cysteine proteases that have vital roles in apoptosis, necrosis and inflammation. Granzyme B belongs to a member of the serine proteinase family and proteolytically cleaves proteins after aspartate residues. Multiple caspase proteins, including caspase 8 (CASP8) and caspase 3 (CASP3), serve as substrates for granzyme B. ${ }^{20,21}$ CASP8 and CASP3 are activated in Fas-mediated cell death and CASP8 is essential for the activation of Bid, a proapoptotic molecule, to induce the release of cytochrome $\mathrm{c}$ from the mitochondria. 22,23 Most PrCas and PrCa cell lines are resistant to Fas ligand-mediated death because Fas is attenuated in androgen-independent or -sensitive $\mathrm{PrCa}$ cells. ${ }^{24,25}$ The loss of Fas therefore abolishes the activation of its downstream apoptotic signaling including the activation of caspases in PrCa.

\section{Results}

Androgen affects the progression of $\mathrm{PrCa}$ and the inactivation of CEBPD was observed in PrCa. To investigate the potential link between CEBPD and the effects of androgen, we first test whether androgen can affect CEBPD transcription through the AR in LNCaP and PC-3 cells. The levels of CEBPD mRNA and protein in LNCaP cells are higher than those in PC-3 cells (Figure 1a), suggesting that the transcription of the CEBPD gene may respond to androgen. A reverse transcription (RT)PCR result showed that DHT can activate the expression of CEBPD in LNCaP cells but not in PC-3 cells (Figure 1b). This result indicated that $C E B P D$ is an androgen-responsive gene and that the AR may be a potent regulator of CEBPD transcription. Various CEBPD reporters were used to assess whether androgen induces the transcription of CEBPD by activating the $C E B P D$ gene promoter. These results indicated that the CEBPD reporter is responsive to DHT. The $5^{\prime}$-serial deletion of $C E B P D$ reporters further indicated that the region between -1000 and -360 -bp upstream of the transcription initiation site of the CEBPD gene contains an androgenresponsive region (Figure 1c). By using the TFsearch applet (http://www.cbrc.jp/research/db/TFSEARCH.html), a potent AR-binding motif (5'-CCGCTGTCC-3') was predicted to be located in the region of -1000 to $-360 \mathrm{bp}$. Next, an in vivo DNA-binding assay showed that AR was responsive to DHT and directly bound to the CEBPD promoter region containing the AR binding motif (Figure 1d).

It has been suggested that the metastasis of PrCas is associated with the AR status and signaling compensation in response to androgen. ${ }^{26,27}$ Epigenetic regulation has a functional role in attenuating the activation of the CEBPD promoter in response to external stimuli. ${ }^{6}$ The expression of E2F1, SUZ12 and EZH2 is associated with the loss of the AR in PC-3 cells (Supplementary Figure S1). Except for the loss of $A R$ regulation, this observation raised speculation that the epigenetic regulation of the E2F1-associated induction of SUZ12/EZH2 may provide another potent regulatory mechanism of CEBPD silencing in AR-deficient or androgeninsensitive PrCa cells.

In clinical samples, from the GSE3325 data set in the public transcriptome, we found that the transcript levels of E2F1 (log2 ratio up to $1.5339, P<0.0001), E Z H 2$ ( $\log 2$ ratio up to 
a
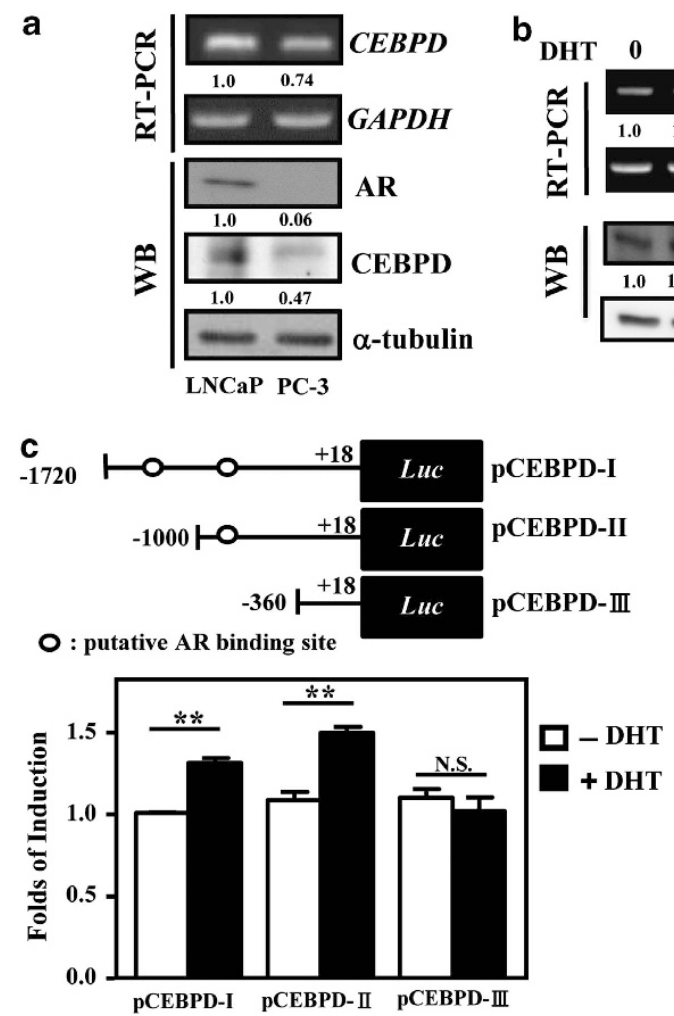

b

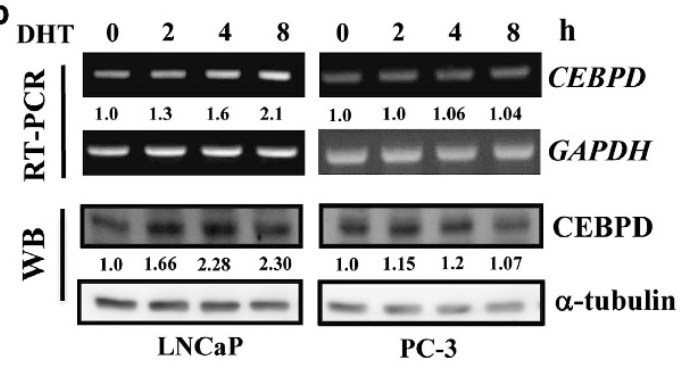

LNCaP

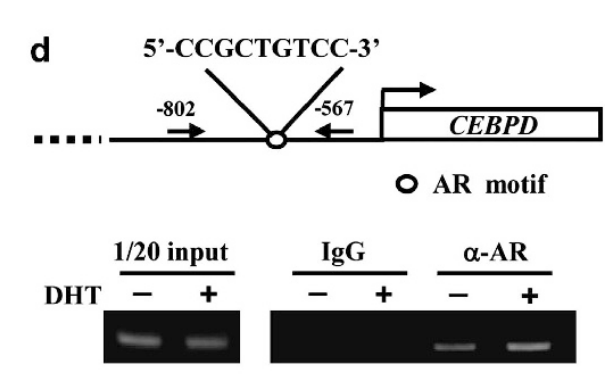

Figure 1 CEBPD is an androgen-responsive gene. (a) The level of CEBPD is associated with the abundance of the AR. RT-PCR analysis and a western blot were conducted to detect the expression of CEBPD and AR, as indicated in LNCaP and PC-3 cells in DMEM supplemented with FBS (without charcoal treatment). (b) DHT stimulates the expression of CEBPD in LNCaP cells but not in PC-3 cells. RT-PCR analysis and western blot were conducted to detect the expression of CEBPD and AR at the indicated time. The LNCaP and PC-3 cells were cultured in DMEM supplemented with charcoal-treated FBS. (c) DHT activates the activity of a CEBPD reporter in LNCaP cells. LNCaP cells were transfected with the reporter pGL2-Basic vector carrying fragments of the CEBPD promoter $(-1720$ to $+18 \mathrm{bp},-1000$ to $+18 \mathrm{bp}$ or -360 to $+18 \mathrm{bp}$ ). After $16 \mathrm{~h}$ of transfection, the transfectants were treated with $10 \mathrm{nM} \mathrm{DHT}$ for $6 \mathrm{~h}$ and the cell lysates were harvested for luciferase assay. Columns, the average of three independent experiments in duplicate measurements; bars, mean \pm S.D. ( ${ }^{\star *} P<0.01$, NS: no significance; Student's t-test). (d) The AR binds to the CEBPD promoter in vivo. A ChIP assay was conducted with the chromatin of $\mathrm{LNCaP}$ cells after $4 \mathrm{~h}$ of treatment with $10 \mathrm{nM}$ DHT. The chromatin of experimental cells was separately immunoprecipitated with control or anti-AR antibodies. The precipitated DNA was then purified and amplified by PCR with the -802 and -567 primers targeting the CEBPD gene locus as indicated. Numbers below the images are the levels normalized to GAPDH (mRNA) or $\alpha$-tubulin (protein)

3.7454, $P<0.0001)$ and SUZ12 (log2 ratio up to 2.8809 , $P<0.0001)$ were significantly upregulated and CEBPD (log2 ratio up to $-1.5702, P<0.0001)$ was significantly downregulated in metastatic PrCa (Supplementary Table S1 and Figure 2a). Notably, the expression of CEBPD was negatively associated with the expression of E2F1, EZH2 and SUZ12 (all $P<0.0001$ ). As shown in Tables 1 and 2 and Figures $2 b$ and $c$, the expression of E2F1, EZH2 and SUZ12 showed stepwise escalation in localized PrCa from low to high stages compared with non-tumor prostate tissue; the expression of CEBPD was significantly downregulated. More importantly, CRPCs also demonstrated significantly elevated levels of E2F1, EZH2 and SUZ12 and decreased CEBPD expression. Furthermore, the negative associations between CEBPD and E2F1, EZH2 and SUZ12 expression levels were further confirmed (Figure 2d).

Increased AR or androgen-insensitive PrCa are commonly observed upon the transition from a hormone-sensitive to a hormone-refractory stage in clinical specimens. LNCaP 104-S cells (AR positive/androgen sensitive) and 104-R1 (AR positive/androgen insensitive) are part of a system established from a relapsed androgen/ablation-resistant $\mathrm{PrCa}$ cell that mimics this clinical situation. ${ }^{5} \mathrm{CEBPD}$ was attenuated in LNCaP 104-R1 cells, although the AR is sustained; this is in contrast with LNCaP 104-S cells (Figure 3a). The silencing of CEBPD was proposed to be through the coupled action of histone and DNA methylation in cervical cancer. ${ }^{6}$ We next tested the effect of these epigenetic changes on CEBPD expression in LNCaP 104-S and 104-R1 cells. In LNCaP 104-R1 cells but not LNCaP 104-S cells, higher levels of E2F1, SUZ12, EZH2 and trimethylated lysine 27 histone 3 were observed; this was inversely correlated with the attenuated CEBPD level (Figure $3 b$ and Supplementary Figure 1). Meanwhile, three major DNA methyltransferases, DNMT1, DNMT3a and DNMT3b, involved in the hypermethylation of gene promoters in tumorigenesis had no changes between LNCaP 104-S and 104-R1 cells (Figure 3b). Unexpectedly, treatment of the cells with the DNA methylation inhibitor 5-AzadC did not reverse the CEBPD transcription in LNCaP 104-R1 cells (Figure 3c). The result suggested that the DNA methylation mediated by the inactivation of CEBPD does not occur in this androgen ablation-resistant PrCa cell system. The result of RT-PCR assay showed that DZNep, an $\mathrm{EZH} 2$ inhibitor, could reverse the inducibility of $C E B P D$ transcripts in LNCaP 104-S1 and -R1 cells (Figure 3d). 
a

Clinically localized primary prostate cancer Metastatic prostate cancer

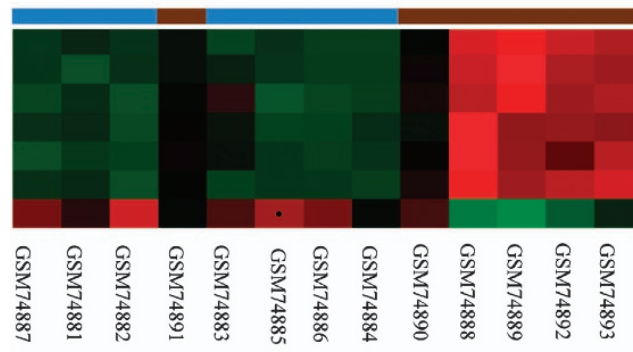

CEBPD negatively correlates with E2F1, SUZ12 and EZH2 (all p<0.001)

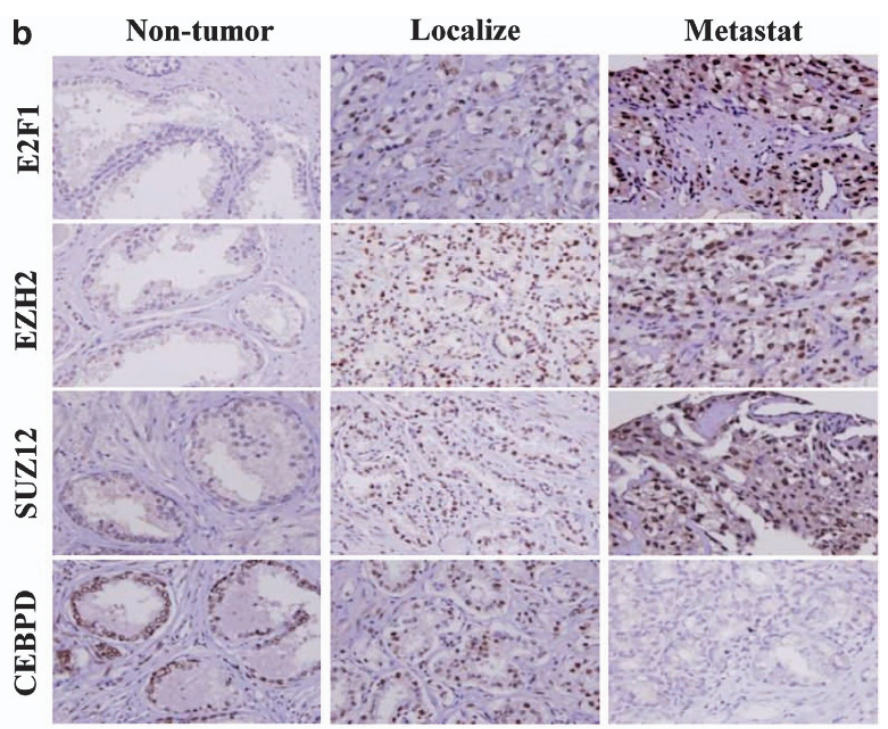

C
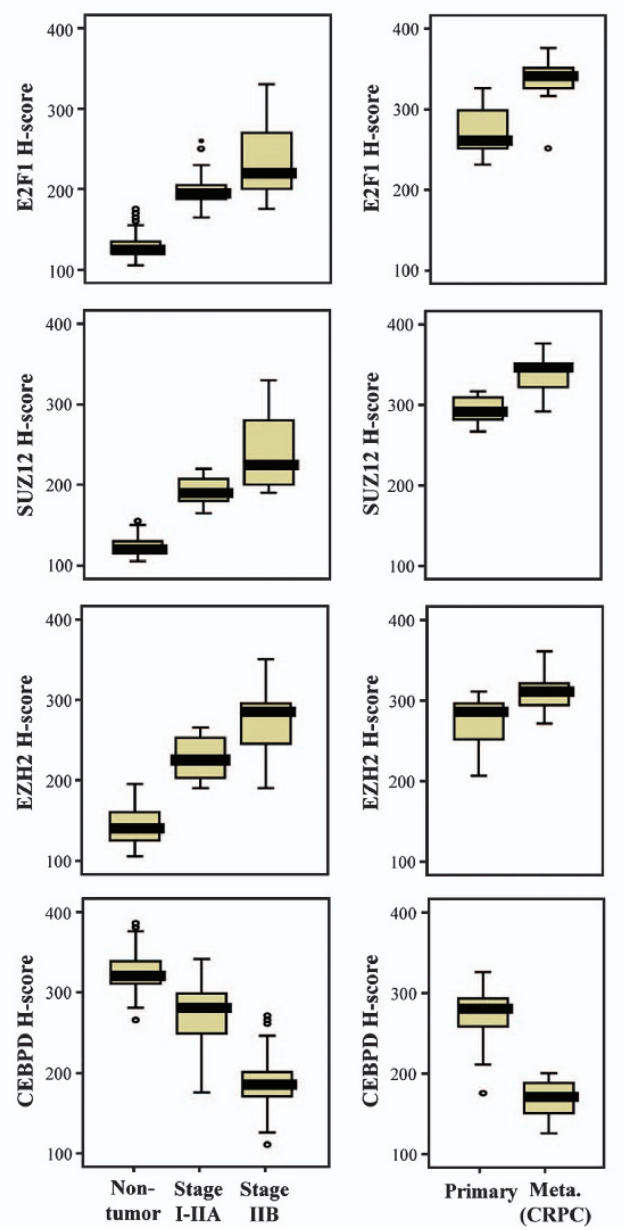

d
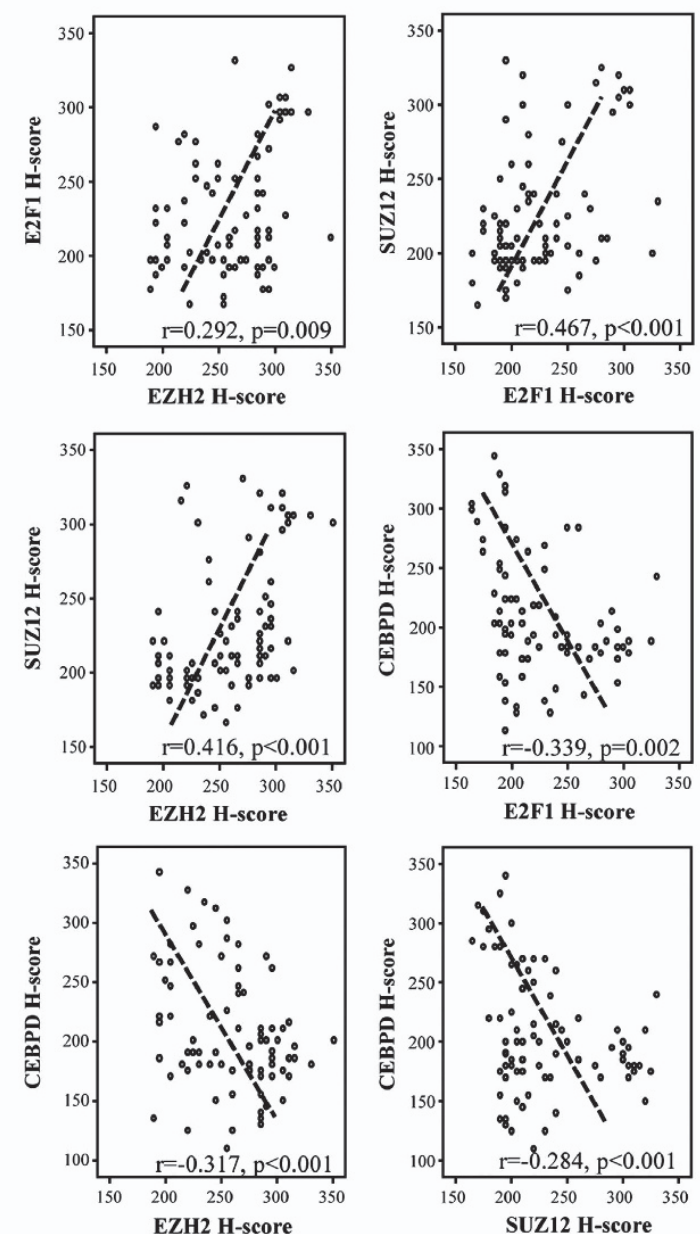

Figure 2 The abundance of CEBPD is negatively associated with the levels of E2F1, EZH2 and SUZ12 in PrCa specimens. (a) By analyzing a published transcriptome data set of metastatic versus localized PrCa samples, E2F1, EZH2 and SUZ12 are significantly upregulated, whereas CEBPD is downregulated in metastatic lesions. Notably, the level of CEBPD transcript is negatively associated with the levels of E2F1, EZH and SUZ12. Primary localized PrCa (blue lines) and metastatic PrCa (brown lines) tissue specimens are indicated on top of the heat map and the relative expression levels of the upregulated and downregulated genes were expressed in the brightness of the red and green colors, respectively, with those genes with unaltered in mRNA expression being colored black. An immunohistochemical study (b) with the statistical analysis (c) of E2F1, EZH2, SUZ12 and CEBPD in representative non-neoplastic prostate tissue (left panel), localized (middle) and metastatic prostate carcinomas shows stepwise increases in E2F1, EZH2 and SUZ12 levels as well as a stepwise downregulation of CEBPD. Furthermore, the positive associations between E2F1, EZH2 and SUZ12 expression levels and their negative association with the CEBPD expression level are also illustrated (d) 
Table 1 Associations between E2F1, EZH2, SUZ12 and CEBPD expression levels with important clinicopathologic variables in two independent data sets

Associations between E2F1, EZH2, SUZ12 and CEBPD expression levels and clinical variables in 80 prostate cancers and paired nontumor tissues

\begin{tabular}{|c|c|c|c|c|c|c|c|c|c|c|}
\hline \multirow[t]{2}{*}{ Parameters } & \multirow[t]{2}{*}{ Category } & \multirow[t]{2}{*}{ Case no. } & \multicolumn{2}{|c|}{ E2F1 LI } & \multicolumn{2}{|c|}{ EZH2 LI } & \multicolumn{2}{|c|}{ SUZ12 LI } & \multicolumn{2}{|c|}{ CEBPD LI } \\
\hline & & & H-score & $P$-value & H-score & $P$-value & H-score & $P$-value & H-score & $P$-value \\
\hline Tissue type & $\begin{array}{l}\text { Non-tumor } \\
\text { Tumor }\end{array}$ & $\begin{array}{l}80 \\
80\end{array}$ & $\begin{array}{l}130.6 \pm 17.27 \\
225.9 \pm 41.34\end{array}$ & & $\begin{array}{l}144.5 \pm 22.59 \\
258.8 \pm 38.89\end{array}$ & $<0.001^{a}$ & $\begin{array}{l}122.9 \pm 11.13 \\
228.9 \pm 44.59\end{array}$ & $<0.001^{a}$ & $\begin{array}{l}323.3 \pm 25.37 \\
206.9 \pm 51.01\end{array}$ & $<0.001^{\mathrm{a}}$ \\
\hline Tumor stage & $\begin{array}{c}\text { Stages I-IIA } \\
\text { Stage } \geq \text { IIB }\end{array}$ & $\begin{array}{l}19 \\
61\end{array}$ & $\begin{array}{l}199.0 \pm 26.49 \\
234.3 \pm 41.69\end{array}$ & $0.002^{\mathrm{a}}$ & $\begin{array}{l}226.1 \pm 27.01 \\
268.9 \pm 36.45\end{array}$ & $<0.001^{\mathrm{a}}$ & $\begin{array}{l}193.4 \pm 16.75 \\
240.0 \pm 44.82\end{array}$ & $<0.001^{a}$ & $\begin{array}{l}270.3 \pm 42.34 \\
187.1 \pm 34.92\end{array}$ & $<0.001^{\mathrm{a}}$ \\
\hline
\end{tabular}

Associations between E2F1, EZH2, SUZ12 and CEBPD expression levels and tumor metastasis in 15 pairs of primary and metastatic prostate cancers

\begin{tabular}{|c|c|c|c|c|c|c|c|c|c|c|}
\hline \multirow[t]{2}{*}{ Parameters } & \multirow[t]{2}{*}{ Category } & \multirow[t]{2}{*}{ Case no. } & \multicolumn{2}{|c|}{ E2F1 LI } & \multicolumn{2}{|c|}{ EZH2 LI } & \multicolumn{2}{|c|}{ SUZ12 LI } & \multicolumn{2}{|c|}{ CEBPD LI } \\
\hline & & & H-score & $P$-value & H-score & $P$-value & H-score & $P$-value & H-score & $P$-value \\
\hline Tumor & $\begin{array}{l}\text { Primary } \\
\text { Metastatic }\end{array}$ & $\begin{array}{l}15 \\
15\end{array}$ & $\begin{array}{l}272.7 \pm 30.81 \\
329.3 \pm 35.25\end{array}$ & $<0.001^{a}$ & $\begin{array}{l}271.3 \pm 36.47 \\
310.3 \pm 24.96\end{array}$ & $0.002^{a}$ & $\begin{array}{l}293.0 \pm 16.78 \\
335.7 \pm 24.56\end{array}$ & $<0.001^{\mathrm{a}}$ & $\begin{array}{l}267.3 \pm 39.68 \\
167.0 \pm 23.28\end{array}$ & $<0.001^{a}$ \\
\hline
\end{tabular}

Mann-Whitney U-test

${ }^{\text {aS }}$ tatistically significant

Table 2 Associations between E2F1, EZH2, SUZ12 and CEBPD expression levels in 80 primary localized prostate cancers

\begin{tabular}{|c|c|c|c|c|c|c|}
\hline \multirow[t]{2}{*}{ Parameters } & \multicolumn{2}{|l|}{ E2F1 LI } & \multicolumn{2}{|l|}{ EZH2 LI } & \multicolumn{2}{|l|}{ SUZ12 LI } \\
\hline & Correlation coefficient & $P$-value & Correlation coefficient & $P$-value & Correlation coefficient & $P$-value \\
\hline $\begin{array}{l}\text { EZH2 LI } \\
\text { SUZ12 LI } \\
\text { CEBPD LI }\end{array}$ & $\begin{array}{c}r=0.292 \\
r=0.467 \\
r=-0.339\end{array}$ & $\begin{array}{r}0.009^{\mathrm{a}} \\
<0.001^{\mathrm{a}} \\
0.002^{\mathrm{a}}\end{array}$ & $\begin{array}{c}-\overline{0.416} \\
r=-0.317\end{array}$ & $\begin{array}{c}<-\bar{c}^{\mathrm{a}} \mathrm{1}^{\mathrm{a}} \\
<0.001^{\mathrm{a}}\end{array}$ & $\begin{array}{c}- \\
r=-0.284\end{array}$ & $\frac{\overline{-}}{<0.001^{2}}$ \\
\hline
\end{tabular}

Pearson's correlation coefficient test

astatistically significant

This suggested that the $\mathrm{EZH} 2-$ mediated histone methylation contributed to LNCaP 104-R1 and LNCaP 104-S1 cells. Importantly, the DZNep treatment showed a more significant effect on reversing the inducibility of $C E B P D$ in response to DHT (Figure 3d, comparing lanes 5 and 6 to lane 4 and lanes 11 and 12 to lane 10). Furthermore, a reporter assay showed that the increases in SUZ12 and EZH2 levels attenuated the DHT-induced CEBPD reporter activity (Supplementary Figure S2). Taken together, these results suggested that a unique involvement of histone methylation on CEBPD silencing in LNCaP-R1 cells.

CEBPD has been reported to be a tumor suppressor and the activation of CEBPD contributes to the induction of apoptosis in $\mathrm{PrCa}^{10}$ However, the detailed mechanism of CEBPD-mediated apoptosis remains uninvestigated in $\mathrm{PrCa}$. $A$ cell death assay showed that the overexpression of CEBPD in LNCaP and PC-3 cells can induce apoptosis and in their individual CEBPD-inducible cell lines, $\mathrm{LNCaP \# 1}$ and PC-3\#1 (Supplementary Figure S3). CASP8 is a death receptor-associated initiator caspase. We found that the transcription of CASP8 but not CASP3 was activated by CEBPD in PC-3 cells (Figure 4a). Furthermore, both procaspase 8 and procaspase 3 proteins were induced after CEBPD induction in LNCaP\#1 and PC3\#1 cells (Figure 4b). Exogenous CEBPD had no effect on $C A S P 3$ reporter activity
(Supplementary Figure S4), but the CASP8 reporter was responsive to CEBPD induction. $A$ marked reduction was observed in pCASP8-II $(-934 /+57)$ and pCASP8-III $(-686 /+57)$ (Figure 4c). This result suggested that the region between -934 and -686 of the CASP8 promoter contains a potent CEBPD-responsive region. The ChIP results showed that CEBPD can directly bind to the CASP8 promoter region (Figure $4 d$ ).

In previous work and this study, we showed that epigenetic effects could attenuate CEBPD activation. Insufficient CEBPD activation will consequently reduce the downstream procaspase levels. To escaping and avoiding these epigenetic and nonspecific effects, a strategy of peptide prodrug was applied to test the death-promoting effect of CEBPD in cancer cells. Perforin (PF) is a pore-forming protein that can assemble into barrel-shaped pores within the cell membrane. These pores have been used for the delivery of toxic compounds or certain proteins into the cells. ${ }^{28,29}$ To develop a more efficient strategy for using the PF-based delivery system to induce death of PrCa cells, we proposed that the combination of increases of procaspase 8 and granzyme B expression levels could enhance the apoptosis cascade for cancer therapy (Supplementary Figure S5).

Prodrugs are substances that are administered in an inactive form, which are subsequently metabolized in vivo 


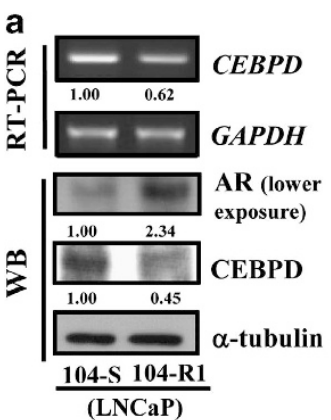

\section{C}

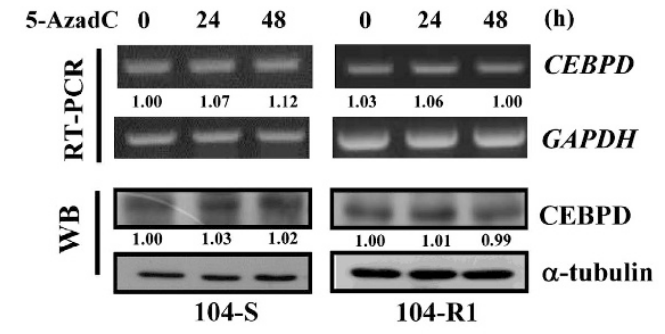

b

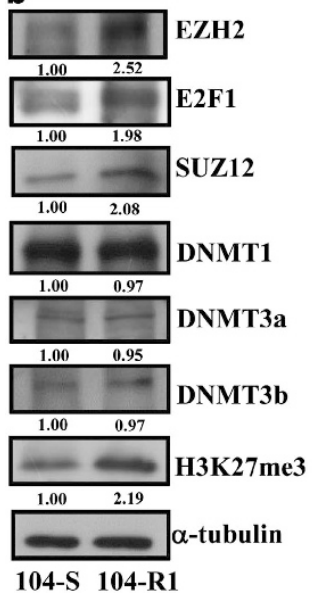

d

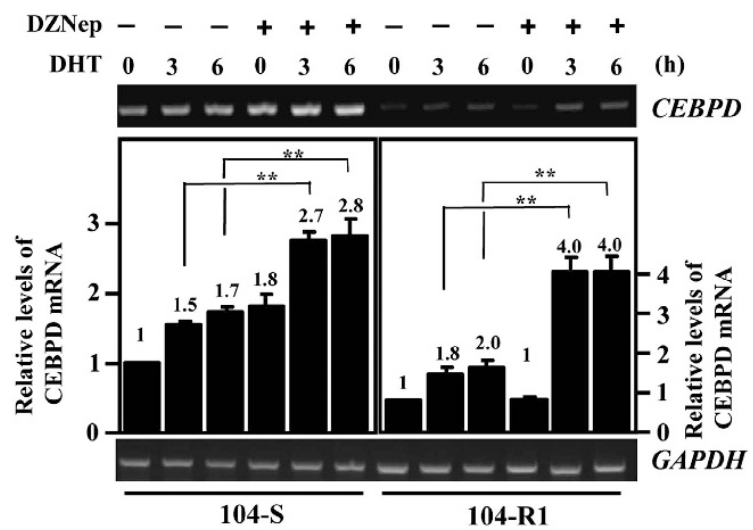

Figure 3 The SUZ12/EZH2-associated histone K27 tri-methylation attenuates DHT-induced CEBPD transcription in PrCa cells. (a) The expression of CEBPD and AR in LNCaP 104-S and 104-R1 cells. RT-PCR and western blot assays were conducted to detect the expression of CEBPD and AR. The LNCaP 104-S (androgen sensitive) and 104-R1 (androgen insensitive) cells were cultured in DMEM supplemented with FBS without charcoal treatment. (b) The endogenous EZH2, E2F1, SUZ12, DNMT1, DNMT3a, DNMT3b and H3K27me3 expression in LNCaP 104-S and 104-R1 cells. Western blot assays were conducted to detect the expression of protein levels. The LNCaP 104-S (androgen sensitive) and 104-R1 (androgen insensitive) cells were cultured in DMEM supplemented with charcoal-treated FBS. (c) The DNA methyltransferase inhibitor 5-AzadC does not reverse the transcription of CEBPD in LNCaP 104-R1 cells. RT-PCR and western blot assays were conducted to detect the expression of CEBPD in response to 5-AzadC in LNCaP 104-S or 104-R1 cells. Two independent experiments were conducted and showed a similar pattern. (d) DHT-stimulated CEBPD transcription was enhanced in cells that were treated with the histone methyltransferase inhibitor DZNep. LNCaP 104S and 104-R1 cells incubated with $1 \mu \mathrm{M}$ DZNep. After $18 \mathrm{~h}$ of treatment, cells were treated with $10 \mathrm{nM}$ DHT and the cell lysates were harvested at the indicated time to perform RT-PCR with specific primers. Three independent experiments were conducted and statistically plotted. Columns, the average of three independent measurements; bars, mean \pm S.D. ( ${ }^{\star *} P<0.01$; Student's $t$-test). Numbers below the images are the levels normalized to GAPDH (mRNA) or $\alpha$-tubulin (protein)

into the active compound. ${ }^{30}$ PF and full-length CEBPD or granzyme $B$ are linked by peptide substrates of PSA or MMP2 to construct PSA-CEBPD (PSA-CD), MMP2-CEBPD (MMP2CD), PSA-granzyme B (PSA-GB) and MMP2-granzyme B (MMP2-GB) expression vectors for producing secretary prodrugs (Figure 5a). The conditioned media from stable Balb/3T3 cells with the above individual expression vectors were harvested to examine the expression levels of these PSA- or MMP2-specific fusion proteins. Western blotting showed that these peptide prodrugs were detectable in the conditioned media (Figure 5b).

Before further testing the effect of conditioned media on inducing apoptosis of PrCa cells, PSA-specific fusion proteins were assessed using a cytotoxicity assay in LNCaP (PSAexpressed and MMP2 positive) and PC-3 (PSA-deficient and MMP2 positive) cells. Both PSA-CD and PSA-GB showed a significantly high toxicity in a dose-dependent manner in LNCaP cells (Supplementary Figure S6A) but not in PC-3 cells. The cytotoxicity assays also showed that both LNCaP and PC-3 cells are sensitive in a dose-dependent manner to the treatment with MMP2-CD and MMP2-GB, respectively (Supplementary Figure S6B). Next, to assess the combination effects of the CEBPD and granzyme B prodrugs in PrCa cells, caspase activation and the cytotoxicity were measured. Briefly, the combination of PSA-CD and PSA-GB showed an additive effect on CASP8 and CASP3/7 activities when compared with PSA-CD and PSA-GB alone in LNCaP cells (Figure 5c, left two panels). In addition, we tested the effects of MMP2-CD and MMP2-GB on the caspase activities of PC-3 cells; the combination of MMP2-CD and MMP2-GB also showed an additive effect on CASP8 and CASP3/7 activities when compared with MMP2-CD and MMP2-GB alone (Figure 5c, right two panels). LNCaP cells were treated with PSA-CD and/or PSA-GB and PC-3 cells were treated with MMP2-CD and/or MMP2-GB. We further assessed the combination of the CEBPD and granzyme $\mathrm{B}$ prodrugs on the cytotoxicity effect of PrCa cells. LNCaP cells that were treated with PSA-CD and PSA-GB alone and the two drugs in combination showed individual viabilities of $48.7 \%, 59.6 \%$ and $14.2 \%$, respectively (Figure $5 d$, upper panel). Moreover, the 


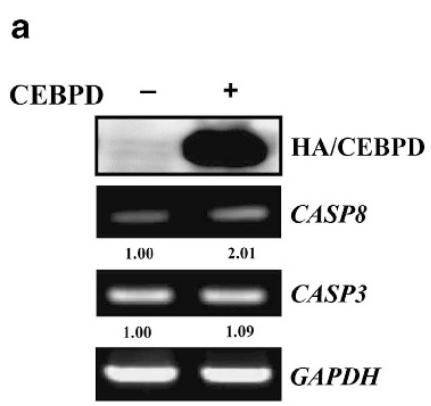

C
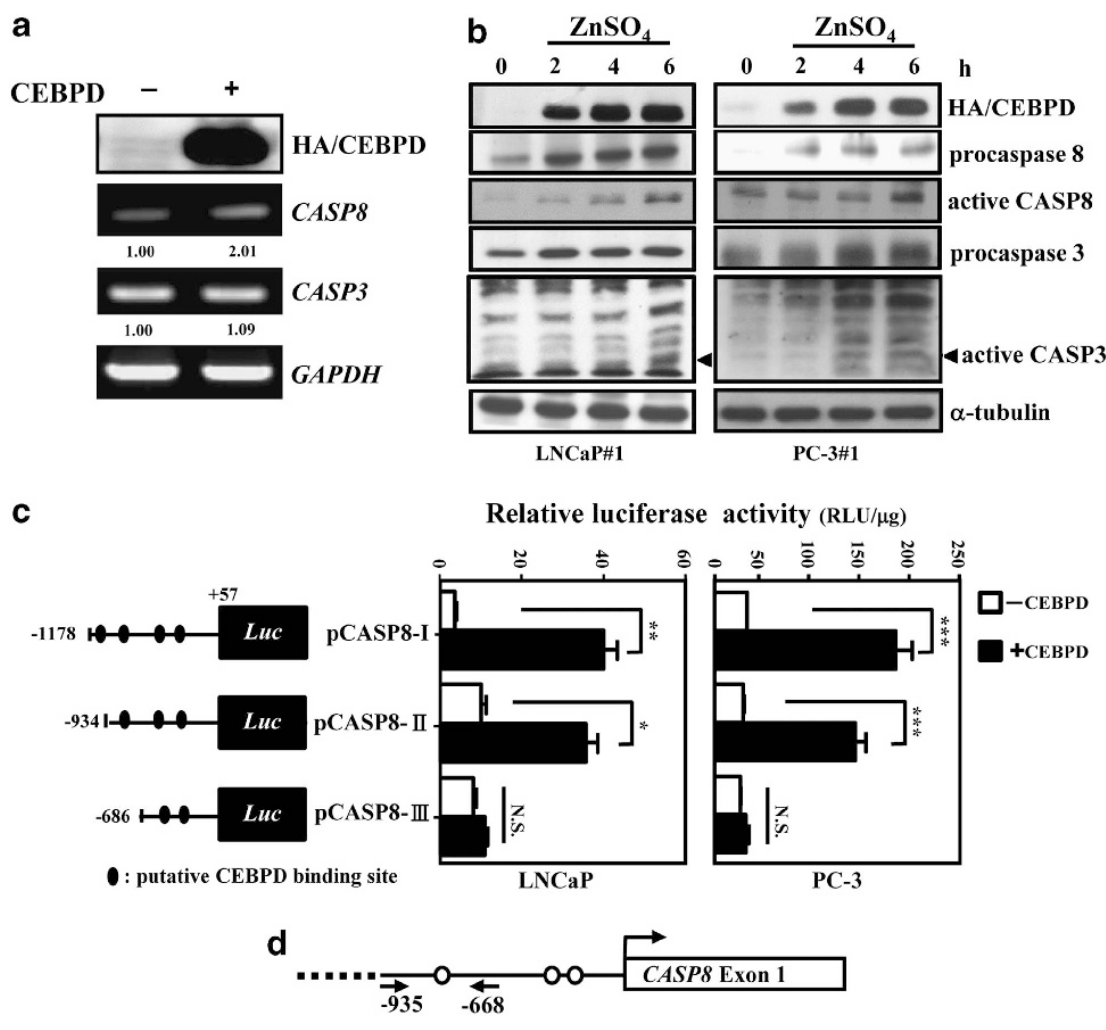

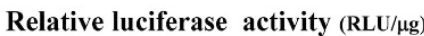

O CEBPD motif

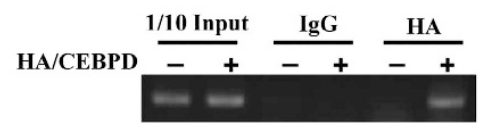

Figure 4 CEBPD activates the transcription of CASP8 but not CASP3 in PrCa cells. (a) CEBPD activates the transcription of CASP8 but not CASP3. An RT-PCR assay was conducted using total RNAs harvested from transfectants with CEBPD or control expression vectors in PC-3 cells. Numbers below the images are the levels normalized to the GAPDH mRNA. (b) CEBPD induces the protein levels of procaspase 8 and procaspase 3 and their activations in LNCaP and PC-3 cells. Stable CEBPD-inducible cells were incubated with $100 \mu \mathrm{M} \mathrm{ZnSO}_{4}$ and total lysates were harvested at the indicated time for western blot analysis with the indicated antibodies. (c) CEBPD contributes to CASP8 reporter activity. The CASP8 reporters were independently co-transfected with CEBPD expression vectors in LNCaP or PC-3 cells. After $16 \mathrm{~h}$ of transfection, the cell lysates were harvested for a luciferase assay. The diagram represents the putative CEBPD-binding sites in the CASP8 promoter region. Columns, the average of three independent measurements in duplicate; bars, mean \pm S.D. $\left({ }^{\star} P<0.05,{ }^{* \star} P<0.01,{ }^{* \star \star} P<0.001\right.$, NS: no significance; Student's $t$-test). (d) In vivo binding of CEBPD to the CASP8 promoter. The scheme of the $5^{\prime}$-flanking regions of the CASP8 gene and the location of primers designed for PCR (right panel). Two independent experiments were conducted and showed a similar pattern

cell viability of LNCaP cells that were treated with MMP2-CD and MMP2-GB alone and in combination showed individual viabilities of $73.4 \%, 76.5 \%$ and $49.7 \%$, respectively (Figure $5 \mathrm{~d}$, bottom panel). These results were consistent with the hypothesis that the combination of CEBPD- and granzyme B-based PF prodrugs can enhance the death of PrCa cells through the augmentation of caspase activation signaling pathway.

\section{Discussion}

CEBPD is low in most cell types and tissues, but it is rapidly induced by several stimulators, as described above. In this study, we further demonstrated that CEBPD is an androgenresponsive gene. Our previous work showed that cAMP response element-binding protein (CREB) has a vital role in CEBPD gene activation. ${ }^{8,31}$ The transcription cofactor p300 and $\mathrm{CREB}$-binding protein (CBP) are ubiquitously expressed proteins that were demonstrated to interact with CREB and
$\mathrm{AR}$ and cooperatively function in the transcriptional regulation of their downstream targeted genes. ${ }^{32}$ A study showed that $A R$ can induce the phosphorylation and transcriptional activity of CREB ${ }^{33}$ In addition, it was proposed that AR participates in the proliferation of prostate epithelial cells. ${ }^{34}$ The observation that CEBPD is an androgen-responsive gene and remains expressed in androgen-dependent LNCaP cells raised some issues, such as the participation of CEBPD in androgenmediated cellular responses, including proliferation and differentiation and the potential role that CEBPD may have as an oncogene in an AR-responsive environment, which may be worthy of further investigation.

The forced overexpression of CEBPD induces growth arrest and apoptosis in cancer cells. ${ }^{6,8}$ Interestingly, our recent results suggested that the level of CEBPD has a dual role in determining long-term TNF $\alpha$-induced tumorigenic transformation. ${ }^{11}$ In this study, DHT does not markedly affect the activation of CEBPD reporter activity, implying that a compromised molecule or signaling is established to support 

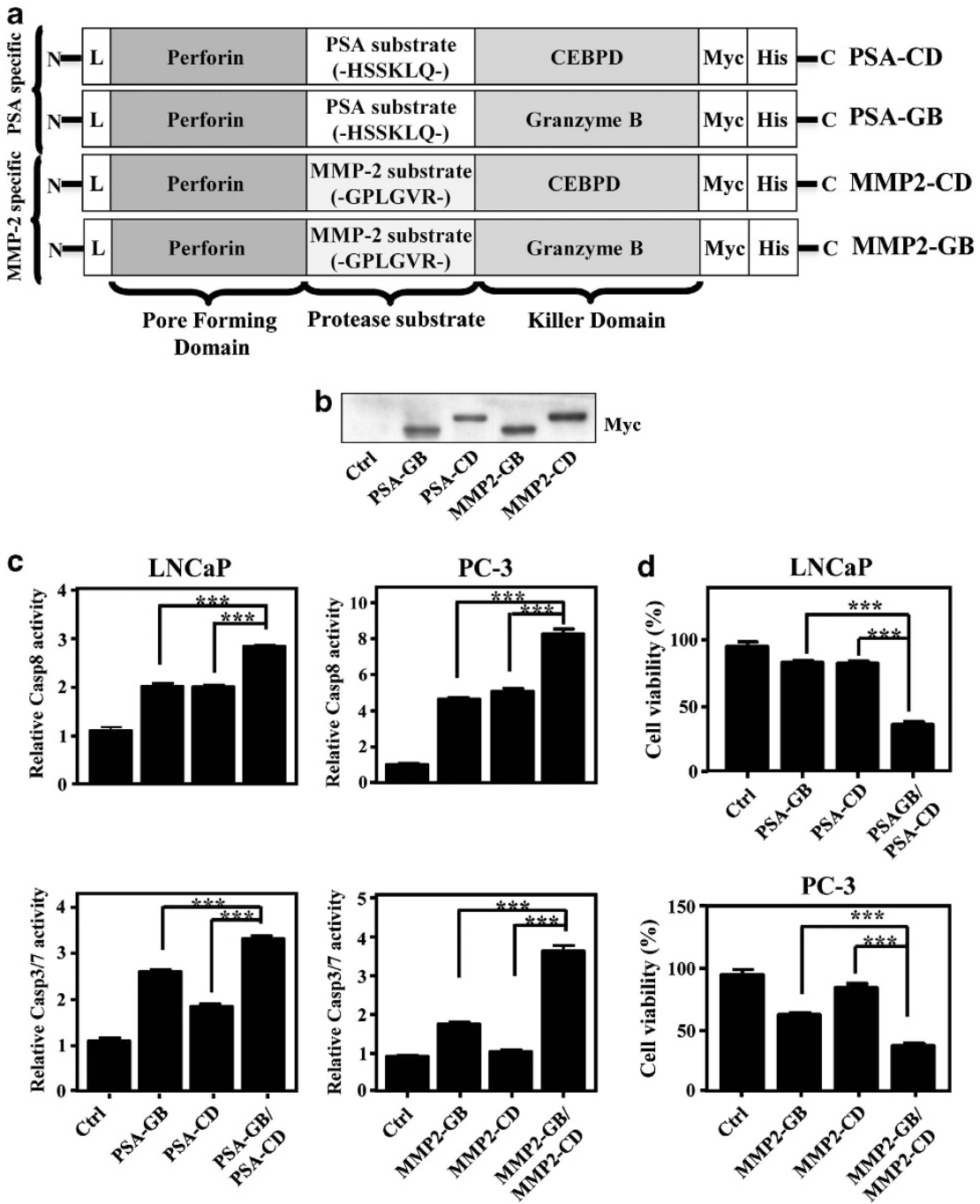

Figure 5 Cooperative effects of the combination treatment of CEBPD and granzyme B in PC3 and LNCaP cells. (a) Scheme of the protease-activated fusion protein. The diagram illustrates the design of the prodrugs PF-CEBPD and PF-granzyme B. PF can form a pore structure at the cell membrane and the protease substrates (PSA, HSSKLQ; MMP2, GPLGVR) can be cleaved by the proteases PSA or MMP2. Once the proteases act, the relaxed CEBPD or granzyme B can enter the cancer cell through the pore formed by PF. L: leader sequence of a murine Ig kappa chain. Myc: c-myc epitope. His: $6 x$ histidine tag. (b) The detection of prodrugs in the supernatant of stably expressing PF-CEBPD and PF-granzyme B 3T3 cells. To generate stable cell lines, all plasmids were co-transfected with pVSVG in GP2-293 cells (Clontech, BD Biosciences, Taiwan) to produce recombinant retroviral particles. After $48 \mathrm{~h}$ of transfection, the culture medium was mixed with $8 \mu \mathrm{g} / \mathrm{ml}$ polybrene and added to $3 T 3 \mathrm{cells}$. Permanent cells were selected with $0.1 \mathrm{mg} / \mathrm{ml} \mathrm{Hygromycin} \mathrm{B} \mathrm{and} \mathrm{sorted} \mathrm{for} \mathrm{high} \mathrm{surface} \mathrm{expression} \mathrm{to} \mathrm{produce} \mathrm{stable} \mathrm{cells.} \mathrm{The} \mathrm{expression} \mathrm{of} \mathrm{protease-specific} \mathrm{fusion} \mathrm{proteins} \mathrm{(PSA-CD,} \mathrm{PSA-}$ GB, MMP2-CD and MMP2-GB) in 3T3 cells was detected by western blot analysis using an anti-c-myc antibody. (c) The combination of prodrugs of granzyme B and CEBPD enhances CASP8 and CASP3 cleavage. LNCaP cells or PC3 cells were plated in serum-free medium in microtiter plates. After $48 \mathrm{~h}$, the LNCaP cells were treated with the culture supernatants of PSA-GB, PSA-CD or a mixture of PSA-GB and PSA-CD. PC3 cells were treated with the supernatants of MMP2-GB, MMP2-CD or mixture of MMP2GB and MMP2-CD in triplicate. The cellular activity of CASP8 or CASP3 was measured via the Caspase-Glo 8 or Caspase-Glo 3 Assay Systems. Columns, the average of three independent measurements in triplicate; bars, mean \pm S.D. ${ }^{* * \star} P<0.001$; Student's $t$-test). (d) The combination of prodrugs of granzyme $B$ and CEBPD represses PrCa cell proliferation. LNCaP cells were treated with the culture supernatants of PSA-GB, PSA-CD or a mixture of PSA-GB and PSA-CD. PC3 cells were treated with the culture supernatants of MMP2-GB, MMP2-CD or mixture of PSA-GB and PSA-CD. The cell viability was determined using the ATPlite kit (Perkin-Elmer, Waltham, MA, USA). Columns, the average of three independent measurements in triplicate; bars, mean \pm S.D. ( ${ }^{* \star *} P<0.001$; Student's $t$-test)

CEBPD existence in the AR-positive or androgen-insensitive environments. The dysregulation of cell cycle regulator E2F1 has been observed in many cancers. An increase of E2F1 has been demonstrated in PrCa cell lines and clinical hormonerefractory PrCa specimens, ${ }^{15}$ although an explanation for the increase of E2F1 in PrCa remains elusive. A study showed that the loss of $\mathrm{Rb}$ was predominantly associated with the transition to the incurable castration-resistant state. ${ }^{35}$ Interestingly, one result showed that the level of E2F1 is increased in Rb-negative PrCa cells, suggesting that Rb may be involved in the regulation of E2F1 levels in PrCa. E2F1 was shown to act as a negative regulator in $A R$ transcription and be inversely correlated with $\mathrm{AR}$ expression in $\mathrm{PrCa}$ cells; ${ }^{15}$ therefore, E2F1 may contribute to the progression of hormone-independent $\mathrm{PrCa}$. In this study, our results showed that higher levels of SUZ12 and EZH2, known E2F1 downstream targets, were observed in LNCaP 104S cell (Figure 3c). 5-AzadC can activate CEBPD transcripts in PC3 
cells. Meanwhile, DZNep can reverse the inducibility of CEBPD by DHT in both PC3 and 104-R1 cells. These results indicated the complexity of epigenetic effects on CEBPD activation in PrCa cells and suggested that there may be a potent anticancer application of DZNep in certain histone methylation-mediated CEBPD silenced cancers. Furthermore, comparing LNCaP 104-S and 104-R1 cells and contrasting those results with those obtained from cervical cancers, we provided a novel discovery that the DNA- and histone-mediated epigenetic regulation of CEBPD transcriptional attenuation can occur in a cell type- or tissue-dependent manner.

CASP8 can induce apoptosis through the activations of CASP3 and intrinsic (mitochondria-mediated) pathway in LNCaP and PC-3 cells. ${ }^{36,37}$ Furthermore, we assessed the involvements of CASP3 activity and mitochondria-mediated pathway in response to CASP8 in our system. The active form of CASP3 and tBid and the release of cytochrome $c$ were responsive to the induction of CEBPD but attenuated in the treatment of specific CASP8 inhibitor (Z-IETD) in LNCaP and PC-3 cells (Supplementary Figure S7). Notably, a study suggested that the cytoplasmic cytochrome $c$ can further activate CASP3 in LNCaP and PC-3 cells. ${ }^{38}$ The results suggest that the activations of CASP3 and mitochondriamediated pathway are involved in CEBPD-induced apoptosis in LNCaP and PC-3 cells (Supplementary Figure S5).

CASP8 protein and mRNA levels are upregulated through the direct binding of CEBPD to the promoter of CASP8 gene. Interestingly, the increase of procaspase-3 protein was unlinked to its transcription when induced by CEBPD (Figures $4 \mathrm{a}$ and $\mathrm{b}$ and Supplementary Figure S4). These results implied that the increase of procaspase 3 could be through a CEBPD-mediated translational regulation. Procaspase 3 was proposed to be a potent substrate of SAG/ROCSCF $\beta$-TrCP E3 Ub ligase, which protects cells from apoptosis by reducing the basal level of procaspase $3 .^{39}$ In addition, the protein F-box/WD repeat-containing protein 7 (Fbxw7) belongs to the F-box protein family and functions as a receptor subunit for SCF (Skp1/Cullin/F-box protein) E3 ubiquitin ligases. The absence of Fbxw7 causes CASP3 activation and increased cell death. ${ }^{40,41}$ Moreover, increases in CEBPD can result in a decrease of FBXW7. ${ }^{7}$ Our preliminary results showed that the decrease of FBXW7 mRNA and the increase of procaspase 3 are associated with the increase of CEBPD (Figure $4 \mathrm{~b}$ and Supplementary Figure S8A). Moreover, the knockdown of FBXW7 showed an increase of procaspase 3 in PC-3 cells (Supplementary Figure S8B). This implied that FBXW7 may mediate the CEBPD-dependent induction of procaspase 3 increase through a post-translational regulation. These observations also implied that the SCF E3 ubiquitin ligases may be another pathway to regulate caspase- 3 activity that can be investigated in the future.

As discussed above, the inactivation of CEBPD has been observed in many cancers; this raises several questions, including whether the activation of CEBPD can result in cancer inhibition and how its full activation could be achieved in cancer cells. As mentioned above, several well-characterized drugs that cause differentiation or induce apoptosis can increase the expression of CEBPD. We recently reported that
CEBPD contributes to the induction of apoptosis in cancer cells through a mechanism involving the pharmacologic effects of the anti-cancer compound 1-(2-hydroxy-5- methylphenyl)-3phenyl-1, 3-propanedione (HMDB). ${ }^{8}$ Several protease substrate drugs have been reported to inhibit the growth of several cancer types. For example, the PSA peptide-substrate conjugated with Doxorubicin ${ }^{42}$ or 5 -flupredeoxyuridine ${ }^{43}$ were synthesized to generate cell-impermeable prodrugs that can be activated by PSA and become cell permeable to kill the PSA overexpressing cancer. Similar results were shown in the MMP2 prodrug. ${ }^{44,45}$ However, the use of a peptide-fused prodrug designed for a target therapy in cancer remains less studied. In addition to PSA, peptidase MMP2 has been suggested to participate in the development and metastasis of PrCa. ${ }^{46,47}$ However, some PrCas express low or no detectable $\mathrm{PSA}^{48}$ Our current results showed that the PSA- and MMP2-based prodrugs are applicable for the therapy of PSA-positive and PSA-negative PrCa, respectively.

Standard antiproliferative chemotherapeutic agents become inefficient against androgen-independent PrCas because the activation of tumor suppressors is not efficiently induced if their promoters are hypermethylated. In addition, as mentioned above, most PrCa cell lines are resistant to Fas-mediated death because Fas is attenuated in AR-independent PrCa cells. Our results successfully showed that an ideal methodology for inducing a heightened apoptotic response in cancer cells by combining CEBPD and granzyme $B$ prodrugs. This strategy can avoid the aforementioned limitations, including (I) the level of death receptor, which is always attenuated or mutated in AR-independent PrCa; (II) the toxicity of chemotherapy anticancer drugs and (III) the complexity of epigenetic effects on the activation of tumor suppressors, such as CEBPD in PrCa.

\section{Materials and Methods}

Cell culture and treatments. The mouse embryonic fibroblast cell line Balb/3T3, the human prostate adenocarcinoma cell line LNCaP and the human PrCa cell line PC-3 were maintained in Dulbecco's modified Eagle's medium (DMEM, Sigma, St. Louis, MO, USA) supplemented with $10 \%$ fetal bovine serum (FBS). LNCaP 104S (AR positive/androgen sensitive) and LNCaP 104R1 (AR positive/androgen insensitive) cells were established, as previously described. ${ }^{5}$ LNCaP 104S was maintained in DMEM supplemented with $10 \%$ FBS and $1 \mathrm{nM}$ DHT and LNCaP 104R1 was maintained in DMEM supplemented with $10 \%$ dextran-coated charcoal-treated FBS. When the cells were $70 \%$ confluent, 5-AzadC $(10 \mu \mathrm{M})$ or DZNep $(1 \mu \mathrm{M})$ was subsequently added to the cells for the designated times. The cells used in all experiments related to $10 \mathrm{nM}$ DHT treatment were maintained under androgen-deprived conditions with complete medium plus dextran-coated charcoal-treated FBS for $24 \mathrm{~h}$.

Reverse transcription-PCR. The isolated RNAs were subjected to RT reactions using SuperScript III (Invitrogen, Carlsbad, CA, USA) for cDNA synthesis. The PCR analysis was performed with the pairs of specific primers as follows:

CEBPD, 5'-AGCGCAACAACATCGCCGTG-3' and 5'-GTCGGGTCTGAGG TATGGGTC-3'; CASP8, 5'-CACGTATGGTGGCTCATGTC-3' and 5'-TTCTG TCACCCAAGCTTGAG-3'; CASP3, 5'-AGGTATCCATGGAGAACACTG-3' and $5^{\prime}$-ACCAGACCGAGATGTCATTCC-3'; and GAPDH, 5'-CCATCACCATCTTCCA GGAG-3' and 5'-CCTGCTTCACCACCTTCTTG-3'

Western blotting. The experimental cells were harvested and lysed in RIPA buffer ( $50 \mathrm{mM}$ Tris- $\mathrm{HCl}$ (pH 7.4), $150 \mathrm{mM} \mathrm{NaCl}, 1 \mathrm{mM}$ EDTA, $1 \%$ Nonidet P-40, $0.25 \%$ sodium deoxycholate, $1 \mathrm{mM}$ DTT, $10 \mathrm{mM}$ sodium fluoride, $1 \mathrm{mM}$ phenylmethylsulfonyl fluoride, aprotinin $1 \mu \mathrm{g} / \mathrm{ml}$, leupeptin $1 \mu \mathrm{g} / \mathrm{ml}$ and $1 \mathrm{mM}$ 
$\mathrm{Na}_{3} \mathrm{VO}_{4}$ ). The proteins were separated by SDS-PAGE, transferred to PVDF membranes and probed with specific antibodies as follows: AR (pg-21, Millipore, Billerica, MA, USA), CEBPD (SC-636, Santa Cruz, Dallas, TX, USA), DNMT1 (IMG-261A, IMGENEX, San Diego, CA, USA), DNMT3A (IMG-268A, IMGENEX), DNMT3B (IMG-184A, IMGENEX), E2F1 (SC-193, Santa Cruz), EZH2 (07-400, Upstate, Billerica, MA, USA), HA (MMS-101R, COVACE, Princeton, NJ, USA), H3K27 trimethylation, (07-449, Upstate), myc (SC-40, Santa Cruz), CASP8 (RB-1200, Thermo Scientific, Pittsburgh, PA, USA), CASP3 (9661, Cell Signaling Technology, Danvers, MA, USA), SUZ12 (07-379, Upstate), tBid (2002, Cell Signaling Technology) and $\alpha$-tubulin (T6199, Sigma). Mitochondrial protein and cytosolic protein were isolated using the Cytochrome c Releasing Apoptosis Assay kit according to the manufacturer's instructions (K257-100, BioVison, San Francisco, CA, USA).

Analysis of published transcriptome data set. To evaluate the transcript levels of E2F1, EZH2, SUZ12 and CEBPD in PrCa and the association between these genes and $\mathrm{PrCa}$ progression, we analyzed one public transcriptome data set of metastatic PrCa samples $(n=6)$ versus localized PrCa samples $(n=7)$. The expression profiling data sets were deposited in Gene Expression Omnibus under the accession number GSE3325. The raw CEL files from the (Affymetrix, Santa Clara, CA, USA) HUMAN Genome U133 Plus 2.0 microarray platform were imported into Nexus Expression 3 software (BioDiscovery, Hawthorne, CA, USA) to analyze all probe sets without pre-selection or filtering.

Patients and tumor specimens. The institutional review board of the Chi-Mei Medical Center approved the procurement of PrCa formalin-fixed tissue for this study (IRB10210002). For the immunohistochemical comparison of primary localized $\mathrm{PrCa}$ and adjacent non-tumor tissue, $80 \mathrm{PrCa}$ patients with available paraffin-embedded tissue blocks were retrieved from the archive of the Chi-Mei Medical Center. To further explore the changes in expression alterations of target proteins, 15 pairs of primary PrCa and CRPC were enrolled.

Immunohistochemical staining and assessment. Tissue sections were cut from paraffin-embedded blocks with a thickness of $3 \mu \mathrm{m}$. Slides were deparaffinized with xylene, rehydrated with ethanol and heated by microwave treatment in a $10 \mathrm{mM}$ citrate buffer $(\mathrm{pH} 6)$ to retrieve the antigen epitopes for 7 min. Endogenous peroxidase was quenched by the treatment with $3 \% \mathrm{H}_{2} \mathrm{O}_{2}$. The slides were washed with Tris-buffered saline for $15 \mathrm{~min}$ and then incubated with a primary monoclonal antibody against E2F1, EZH2, SUZ12 or CEBPD. The immunoexpression was scored using $\mathrm{H}$-score. The $\mathrm{H}$-score was calculated using the following equation: $\mathrm{H}$-score $=\sum \mathrm{Pi}^{*}(i+1)$, where $i$ is the intensity score (which ranged $0-4$ ) and $\mathrm{Pi}$ is the percentage of stained tumor cells with each intensity score (which ranged from 0 to $100 \%$ ). The resulting score ranged from 100 to 500 ; a score of 100 indicates that $100 \%$ of the tumor cells were negative $(0)$ and a score of 500 indicates that $100 \%$ of the tumor cells were strongly stained $(4+)$.

Plasmid transfection and reporter gene assay. The indicated cells were transfected with plasmids using the Turbofect transfection reagent according to the manufacturer's instructions. Transfectants were cultured in medium as described above with or without treatments and harvested at the indicated time. The luciferase activity of the transfectants was measured using the Luciferase Assay System (Promega, Madison, WI, USA) according to the manufacturer's instructions.

Chromatin immunoprecipitation. The ChIP assay ${ }^{49}$ was carried out essentially as described by Wang et al. ${ }^{50}$ Briefly, cells were treated with $1 \%$ formaldehyde for $15 \mathrm{~min}$. The cross-linked chromatin was then prepared and sonicated to an average size of $300-500 \mathrm{bp}$. DNA fragments were immunoprecipitated with antibodies that were specific for HA, CEBPD or control immunoglobulin $\mathrm{G}$ at $4{ }^{\circ} \mathrm{C}$ overnight. The cross-linking was reversed and the immunoprecipitated chromatin was amplified using primers corresponding to specific regions in the CEBPD genomic locus. The ChIP primers for the CEBPD promoter were as follows: $5^{\prime}$-CATCTGCTCTGCTTTTGGCGACA-3' ${ }^{\prime}$ and 5'- TGGGACCAGATGCGGGAAGAG-3'. The ChIP primers for the CASP8 promoter were as follows: $5^{\prime}$-GGACTTGGAGCTCAGATGCAACAC- $3^{\prime}$ and 5'- CTCAGTGCCTTCCTCGGCTCATTC-3'.

Flow cytometry analysis. Metallothionein-inducible CEBPD PC-3 and $\mathrm{LNCaP}$ cells were treated with $100 \mu \mathrm{M} \mathrm{ZnSO}_{4}$ for $24 \mathrm{~h}$. The cells were suspended in PBS and fixed in ice-cold $100 \%$ ethanol at $20^{\circ} \mathrm{C}$. Later, the cell pellets were collected by centrifugation and resuspended in propidium iodide (PI) solution $(0.1 \%$ Triton X-100 in PBS, $0.2 \mathrm{mg} / \mathrm{ml}$ of RNase A and $20 \mathrm{mg} / \mathrm{ml}$ of PI) at room temperature for $1 \mathrm{~h}$. The fluorescence emitted from the PI-DNA complexes was measured after excitation of the fluorescent dye by FACScan cytometry (BD Biosciences, Franklin Lakes, NJ, USA).

Generation of protease-specific prodrugs. Individual coding DNA fragments, including PF (1-515 amino acids), peptide substrate of PSA (GPLGVR), peptide substrate of MMP-2 (HSSKLQ), a granzyme B cDNA and a CEBPD CDNA, were cloned into a pLHCX vector. Later, the expression vectors were co-transfected with pVSVG expression vector into GP2-293 cells (Clontech, Mountain View, CA, USA) to produce recombinant retroviral particles for the infection of 3 T3 cells and to generate stable cell lines expressing PSA-specific fusion proteins or MMP-specific fusion proteins.

CASP3 and CASP8 activity assay and cell proliferation assays. A total of $1 \times 10^{4} \mathrm{LNCaP}$ or PC-3 cells were treated with conditioned medium with secreted PSA or MMP-specific fusion proteins or control mock in triplicate and then incubated at $37^{\circ} \mathrm{C}$ for $8 \mathrm{~h}$. Later, the experimental cells were analyzed using the caspase-Glo $3 / 7$ or caspase-Glo 8 reagents (Promega) according to the manufacturer's instructions. For the proliferation assay, the experimental cells were analyzed using a CCK-8 kit (Sigma) following to the manufacturer's instructions.

Statistical analysis. Statistical significance of differences between mean values was estimated using the InStat software (version 3.0; GraphPad Software, La Jolla, CA, USA) using the independent Student's $t$-test for unequal variances. $P$-values of $<0.05$ were considered to be statistically significant.

\section{Conflict of Interest}

The authors declare no conflict of interest.

Acknowledgements. This work was supported, in whole or in part, by grant NHRI-EX102-10143NI from the National Health Research Institutes, grant NSC100-2320-B-006-020 from the National Science Council, Ministry of Health and Welfare (MOHW103-TD-B-111-05) and the Headquarters of University Advancement at the National Cheng Kung University from the Ministry of Education. We thank Dr. Tsunglin Liu at National Cheng Kung University for the inputs during the preparation of the manuscript.

1. Feldman BJ, Feldman D. The development of androgen-independent prostate cancer. Nat Rev Cancer 2001; 1: 34-45.

2. Montgomery RB, Mostaghel EA, Vessella R, Hess DL, Kalhorn TF, Higano CS et al. Maintenance of intratumoral androgens in metastatic prostate cancer: a mechanism for castration-resistant tumor growth. Cancer Res 2008; 68: 4447-4454.

3. van der Kwast TH, Schalken J, Ruizeveld de Winter JA, van Vroonhoven CC, Mulder E, Boersma $\mathrm{W}$ et al. Androgen receptors in endocrine-therapy-resistant human prostate cancer. Int J Cancer 1991; 48: 189-193.

4. Koivisto P, Kononen J, Palmberg C, Tammela T, Hyytinen E, Isola J et al. Androgen receptor gene amplification: a possible molecular mechanism for androgen deprivation therapy failure in prostate cancer. Cancer Res 1997; 57: 314-319.

5. Kokontis JM, Hay N, Liao S. Progression of LNCaP prostate tumor cells during androgen deprivation: hormone-independent growth, repression of proliferation by androgen, and role for p27Kip1 in androgen-induced cell cycle arrest. Mol Endocrinol 1998; 12: 941-953.

6. Ko CY, Hsu HC, Shen MR, Chang WC, Wang JM. Epigenetic silencing of CCAAT/ enhancer-binding protein delta activity by $\mathrm{YY} 1 /$ polycomb group/DNA methyltransferase complex. J Biol Chem 2008; 283: 30919-30932.

7. Balamurugan K, Wang JM, Tsai HH, Sharan S, Anver M, Leighty R et al. The tumour suppressor C/EBPdelta inhibits FBXW7 expression and promotes mammary tumour metastasis. EMBO J 2010; 29: 4106-4117.

8. Pan YC, Li CF, Ko CY, Pan MH, Chen PJ, Tseng JT et al. CEBPD reverses RB/E2F1-mediated gene repression and participates in HMDB-induced apoptosis of cancer cells. Clin Cancer Res 2010; 16: 5770-5780.

9. Hour TC, Lai YL, Kuan Cl, Chou CK, Wang JM, Tu HY et al. Transcriptional up-regulation of SOD1 by CEBPD: a potential target for cisplatin resistant human urothelial carcinoma cells. Biochem Pharmacol 2010; 80: 325-334.

10. Ikezoe T, Gery S, Yin D, O'Kelly J, Binderup L, Lemp N et al. CCAAT/enhancer-binding protein delta: a molecular target of 1,25-dihydroxyvitamin D3 in androgen-responsive prostate cancer LNCaP cells. Cancer Res 2005; 65: 4762-4768. 
11. Wu SR, Li CF, Hung LY, Huang AM, Tseng JT, Tsou JH et al. CCAAT/enhancer-binding protein delta mediates tumor necrosis factor alpha-induced Aurora kinase $\mathrm{C}$ transcription and promotes genomic instability. J Biol Chem 2011; 286: 28662-28670.

12. Sivko GS, DeWille JW. CCAAT/enhancer binding protein delta (c/EBPdelta) regulation and expression in human mammary epithelial cells: I. "Loss of function" alterations in the c/EBPdelta growth inhibitory pathway in breast cancer cell lines. J Cell Biochem 2004; 93 : 830-843.

13. Tang D, Sivko GS, DeWille JW. Promoter methylation reduces C/EBPdelta (CEBPD) gene expression in the SUM-52PE human breast cancer cell line and in primary breast tumors. Breast Cancer Res Treat 2006; 95: 161-170.

14. Agrawal S, Hofmann WK, Tidow N, Ehrich M, van den Boom D, Koschmieder S et al. The C/EBPdelta tumor suppressor is silenced by hypermethylation in acute myeloid leukemia. Blood 2007; 109: 3895-3905

15. Davis JN, Wojno KJ, Daignault S, Hofer MD, Kuefer R, Rubin MA et al. Elevated E2F1 inhibits transcription of the androgen receptor in metastatic hormone-resistant prostate cancer. Cancer Res 2006; 66: 11897-11906.

16. Bracken AP, Pasini D, Capra M, Prosperini E, Colli E, Helin K. EZH2 is downstream of the pRB-E2F pathway, essential for proliferation and amplified in cancer. EMBO J 2003; 22: 5323-5335.

17. Cao R, Zhang Y. SUZ12 is required for both the histone methyltransferase activity and the silencing function of the EED-EZH2 complex. Mol Cell 2004; 15: 57-67.

18. Trudel D, Fradet $Y$, Meyer F, Harel F, Tetu B. Significance of MMP-2 expression in prostate cancer: an immunohistochemical study. Cancer Res 2003; 63: 8511-8515.

19. Varani J, Hattori Y, Dame MK, Schmidt T, Murphy HS, Johnson KJ et al. Matrix metalloproteinases (MMPs) in fresh human prostate tumour tissue and organ-cultured prostate tissue: levels of collagenolytic and gelatinolytic MMPs are low, variable and different in fresh tissue versus organ-cultured tissue. $\mathrm{Br} J$ Cancer 2001; 84: 1076-1083.

20. Medema JP, Toes RE, Scaffidi C, Zheng TS, Flavell RA, Melief CJ et al. Cleavage of FLICE (caspase-8) by granzyme B during cytotoxic T lymphocyte-induced apoptosis Eur J Immunol 1997; 27: 3492-3498.

21. Yang X, Stennicke HR, Wang B, Green DR, Janicke RU, Srinivasan A et al. Granzyme B mimics apical caspases. Description of a unified pathway for trans-activation of executione caspase-3 and -7. J Biol Chem 1998; 273: 34278-34283.

22. Li H, Zhu H, Xu CJ, Yuan J. Cleavage of BID by caspase 8 mediates the mitochondrial damage in the Fas pathway of apoptosis. Cell 1998; 94: 491-501.

23. Luo X, Budihardjo I, Zou H, Slaughter C, Wang X. Bid, a Bcl2 interacting protein, mediates cytochrome $\mathrm{c}$ release from mitochondria in response to activation of cell surface death receptors. Cell 1998; 94: 481-490.

24. Frost PJ, Belldegrun A, Bonavida B. Sensitization of immunoresistant prostate carcinoma cell lines to Fas/Fas ligand-mediated killing by cytotoxic lymphocytes: independence of de novo protein synthesis. Prostate 1999; 41: 20-30.

25. Costa-Pereira AP, Cotter TG. Camptothecin sensitizes androgen-independent prostate cancer cells to anti-Fas-induced apoptosis. Br J Cancer 1999; 80: 371-378.

26. Jin HJ, Zhao JC, Ogden I, Bergan RC, Yu J. Androgen receptor-independent function of FoxA1 in prostate cancer metastasis. Cancer Res 2013; 73: 3725-3736.

27. Hodgson MC, Bowden WA, Agoulnik IU. Androgen receptor footprint on the way to prostate cancer progression. World J Urol 2012; 30: 279-285.

28. Kurschus FC, Jenne DE. Delivery and therapeutic potential of human granzyme B. Immunol Rev 2010; 235: 159-171.

29. Thiery J, Keefe D, Saffarian S, Martinvalet D, Walch M, Boucrot E et al. Perforin activates clathrin- and dynamin-dependent endocytosis, which is required for plasma membrane repair and delivery of granzyme B for granzyme-mediated apoptosis. Blood 2010; 115 1582-1593.

30. Choi KY, Swierczewska M, Lee S, Chen X. Protease-activated drug development Theranostics 2012; 2: 156-178.

31. Wang JM, Tseng JT, Chang WC. Induction of human NF-IL6beta by epidermal growth factor is mediated through the $\mathrm{p} 38$ signaling pathway and cAMP response element-binding protein activation in A431 cells. Mol Biol Cell 2005; 16: 3365-3376.

32. Santer FR, Hoschele PP, Oh SJ, Erb HH, Bouchal J, Cavarretta IT et al. Inhibition of the acetyltransferases p300 and CBP reveals a targetable function for p300 in the survival and invasion pathways of prostate cancer cell lines. Mol Cancer Ther 2011; 10 1644-1655

33. Genua M, Pandini G, Sisci D, Castoria G, Maggiolini M, Vigneri R et al. Role of cyclic AMP response element-binding protein in insulin-like growth factor-i receptor up-regulation by sex steroids in prostate cancer cells. Cancer Res 2009; 69: 7270-7277.
34. Waltregny D, Leav I, Signoretti S, Soung P, Lin D, Merk F et al. Androgen-driven prostate epithelial cell proliferation and differentiation in vivo involve the regulation of p27. Mol Endocrinol 2001; 15: 765-782.

35. Sharma A, Yeow WS, Ertel A, Coleman I, Clegg N, Thangavel C et al. The retinoblastoma tumor suppressor controls androgen signaling and human prostate cancer progression. J Clin Invest 2010; 120: 4478-4492.

36. Guseva NV, Taghiyev AF, Rokhlin OW, Cohen MB. Contribution of death receptor and mitochondrial pathways to Fas-mediated apoptosis in the prostatic carcinoma cell line PC3. Prostate 2002; 51: 231-240.

37. Eid MA, Lewis RW, Kumar MV. Mifepristone pretreatment overcomes resistance of prostate cancer cells to tumor necrosis factor alpha-related apoptosis-inducing ligand (TRAIL). Mol Cancer Ther 2002; 1: 831-840.

38. Nakata S, Yoshida T, Shiraishi T, Horinaka M, Kouhara J, Wakada M et al. 15-DeoxyDelta12,14-prostaglandin $\mathrm{J}(2)$ induces death receptor 5 expression through mRNA stabilization independently of PPARgamma and potentiates TRAIL-induced apoptosis. Mol Cancer Ther 2006; 5: 1827-1835.

39. Tan M, Gallegos JR, Gu Q, Huang Y, Li J, Jin Y et al. SAG/ROC-SCF beta-TrCP E3 ubiquitin ligase promotes pro-caspase-3 degradation as a mechanism of apoptosis protection. Neoplasia 2006; 8: 1042-1054.

40. Babaei-Jadidi R, Li N, Saadeddin A, Spencer-Dene B, Jandke A, Muhammad B et al. FBXW7 influences murine intestinal homeostasis and cancer, targeting Notch, Jun, and DEK for degradation. J Exp Med 2011; 208: 295-312.

41. Hoeck JD, Jandke A, Blake SM, Nye E, Spencer-Dene B, Brandner S et al. Fbw7 controls neural stem cell differentiation and progenitor apoptosis via Notch and c-Jun. Nat Neurosci 2010; 13: 1365-1372.

42. DiPaola RS, Rinehart J, Nemunaitis J, Ebbinghaus S, Rubin E, Capanna T et al. Characterization of a novel prostate-specific antigen-activated peptide-doxorubicin conjugate in patients with prostate cancer. J Clin Oncol 2002; 20: 1874-1879.

43. Mhaka A, Denmeade SR, Yao W, Isaacs JT, Khan SR. A 5 -fluorodeoxyuridine prodrug as targeted therapy for prostate cancer. Bioorg Med Chem Lett 2002; 12: 2459-2461.

44. Albright CF, Graciani N, Han W, Yue E, Stein R, Lai Z et al. Matrix metalloproteinaseactivated doxorubicin prodrugs inhibit HT1080 xenograft growth better than doxorubicin with less toxicity. Mol Cancer Ther 2005; 4: 751-760.

45. Stern L, Perry R, Ofek P, Many A, Shabat D, Satchi-Fainaro R. A novel antitumor prodrug platform designed to be cleaved by the endoprotease legumain. Bioconjug Chem 2009; 20 : 500-510

46. Ross JS, Kaur P, Sheehan CE, Fisher HA, Kaufman Jr RA, Kallakury BV. Prognostic significance of matrix metalloproteinase 2 and tissue inhibitor of metalloproteinase 2 expression in prostate cancer. Mod Pathol 2003; 16: 198-205.

47. Trudel D, Fradet Y, Meyer F, Harel F, Tetu B. Membrane-type-1 matrix metalloproteinase, matrix metalloproteinase 2, and tissue inhibitor of matrix proteinase 2 in prostate cancer: identification of patients with poor prognosis by immunohistochemistry. Hum Pathol 2008; 39: $731-739$

48. Qin J, Liu X, Laffin B, Chen X, Choy G, Jeter CR et al. The PSA(-/lo) prostate cancer cell population harbors self-renewing long-term tumor-propagating cells that resist castration. Cell Stem Cell 2012; 10: 556-569.

49. Fletcher K L Lord PG, Orton TC, Chipman JK, Strain AJ. EGF-Induced receptor autophosphorylation in primary hepatocytes isolated from phenobarbitone-treated mice. Biochem Biophys Res Commun 1999; 260: 483-487.

50. Wang WL, Lee YC, Yang WM, Chang WC, Wang JM. Sumoylation of LAP1 is involved in the HDAC4-mediated repression of COX-2 transcription. Nucleic Acids Res 2008; 36: 6066-6079.

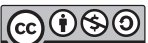

Cell Death and Disease is an open-access journal published by Nature Publishing Group. This work is licensed under a Creative Commons Attribution-NonCommercialShareAlike 3.0 Unported License. The images or other third party material in this article are included in the article's Creative Commons license, unless indicated otherwise in the credit line; if the material is not included under the Creative Commons license, users will need to obtain permission from the license holder to reproduce the material. To view a copy of this license, visit http://creativecommons.org/licenses/ by-nc-sa/3.0/ 